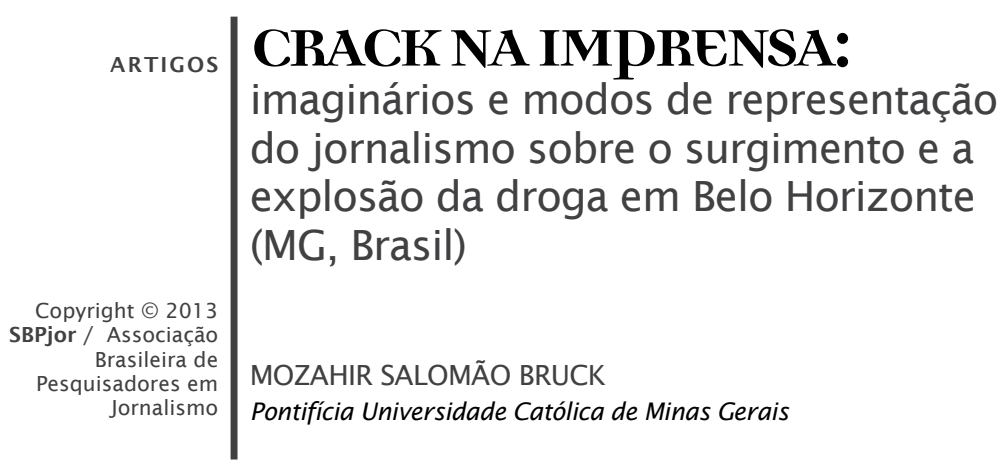

RESUMO - Este artigo apresenta resultados de investigação sobre a cobertura pelo jornal Estado de Minas, considerado periódico de referência da cidade de Belo Horizonte (Minas Gerais, Brasil), do uso e comércio do crack no município. Para tal, valemo-nos de referenciais teóricos originados das ciências sociais e, em específico, das teorias do jornalismo. Na pesquisa, que cobriu 15 anos de edições do jornal Estado de Minas, a analítica de conteúdo parametrizou a constituição do corpus, bem como sua análise e interpretação. O objetivo de tal levantamento foi tentar compreender que imagens são construídas pelo jornalismo sobre o chamado submundo do crack - a droga, seus atores e as complexas redes de distribuição, usos, combate, prevenção e tratamento, sabendo que, de um modo ou de outro, tais percepções - engendradas pelo discurso jornalístico - têm efetivamente impacto junto à sociedade que consome e faz circular os enunciados presentes nesse discurso.

Palavras-Chave: Jornalismo. Crack. Imaginário social. Jornal Estado de Minas.

Crac en la prensa: imaginarios y modos de representación del periodismo sobre el surgimiento y la explosión de la droga en Belo Horizonte (Minas Gerais, Brasil)

RESUMEN - Este artículo presenta los resultados de la investigación sobre la cobertura del diario Estado de Minas, considerado un periódico de referencia en la ciudad de Belo Horizonte (Minas Gerais, Brasil), sobre el uso y el comercio del crac en el municipio. Con este fin, hacemos uso de marcos teóricos derivados de las ciencias sociales y, en particular, de las teorías del periodismo. En la investigación, que abarcó quince años de ediciones del diario Estado de Minas, el análisis del contenido determinó los parámetros para la formación del corpus y su posterior análisis e interpretación. El propósito de este estudio fue tratar de comprender qué imágenes construye el periodismo sobre el llamado submundo del crac - la droga, sus actores y las complejas redes de distribución, sus usos, la lucha, la prevención y el tratamiento- ya que, de una manera u otra, tales percepciones tienen, efectivamente, un impacto en la sociedad, la cual consume y hace circular los enunciados presentes en ese discurso periodístico.

Palabras clave: Periodismo. Crac. Imaginario social. Diario Estado de Minas.

CRACK IN THE PRESS: journalism's representations and imaginary of the advent and explosion of the drug in Belo Horizonte (MG, Brazil)

ABSTRACT - This article reports research results from an investigation into the coverage given by the Estado de Minas newspaper - reputed to be a leading opinion maker in the state - on crack usage and commerce in Belo Horizonte, the state capital. Theoretical references adopted originated from social sciences and, in particular, from the theories of journalism. In the research, which covered 15 years the daily newspaper Estado de Minas issues, the analytic content configured the constitution of the corpus, as well as its analysis and interpretation. The aim was to understand the way journalism portrays the underworld of crack and refers to the drug, to its actors, and to its complex networks of distribution, usage, power struggles, prevention and treatment. The objective based on the assumption that, in one way or another, the perceptions engendered by the journalistic discourse effectively have an impact on the society in which the discourse circulates.

Keywords: Journalism. Crack. Social imaginary. Estado de Minas Newspaper 


\section{CONSIDERAÇÕES TÁTICAS}

Este artigo apresenta resultados de pesquisa' sobre a cobertura pelo diário Estado de Minas, considerado jornal de referência ${ }^{2}$ da cidade de Belo Horizonte (Minas Gerais, Brasil), do uso e da venda do crack no município. Nossa hipótese inicial foi a de que a cobertura sobre o fenômeno do crack - cujos impactos sociais, econômicos, de segurança e de saúde pública têm se amplificado em todo o Brasil ${ }^{3}$ - acaba por reforçar, em função de características e peculiaridades próprias do fazer jornalístico e das narrativas produzidas por este campo e pelo modo como as mídias se fazem presentes na sociedade, de modo enviesado, aspectos mais agudizados da questão e, em determinados momentos e circunstâncias, mais opacizando do que contribuindo para uma melhor compreensão e debate sobre a droga.

Nesse sentido, o trabalho dos pesquisadores foi tentar compreender que imagens são construídas pelo jornalismo sobre o chamado submundo do crack - a droga, seus atores e as complexas redes de distribuição, usos, combate, prevenção e tratamento, sabendo que, de um modo ou de outro, tais narrativas têm efetivamente impacto junto à sociedade que as consome, faz circular e reverbera os sentidos ofertados por esse discurso.

$\mathrm{Na}$ delimitação do corpus para análise4, tomou-se como elementos de observação textos noticiosos publicados pelo Estado de Minas entre os anos de 1996 e 2011 - notas, notícias e reportagens - que, como se detalhará nos procedimentos metodológicos, foram classificados segundo o modo e a relevância com que o tema crack foi tratado. A droga, ao longo desse período, nesse conjunto de matérias jornalísticas, foi abordada das mais diferentes perspectivas, como a formação de locais de reunião de crackeiros, denominados já em todo o Brasil como "cracolândias"; o impacto do crack na vida dos usuários; o envolvimento de policiais com a droga; e a luta dos familiares e amigos para a recuperação dos viciados.

O levantamento quantitativo 5 contribuiu para revelar o aumento do interesse da imprensa pela cobertura do crack na medida em que a droga foi intensificando seus impactos na sociedade - seja em termos da presença do usuário nas ruas, seja nas questões de saúde pública, especialmente, da associação da droga à violência e ao crime. Já a abordagem do conteúdo das narrativas do Estado de Minas6 foi ao encontro de nosso objetivo de analisar as alusões do jornal ao crack, bem como aos agentes que orbitam em torno da droga (usuários, terapeutas, 
agentes de saúde, policiais etc.) e de como, de algum modo, tais narrativas contribuem para alimentar mitos e imaginários presentes no senso comum em relação à droga, proporcionando efetiva oportunidade de reflexão acerca dos modos como a imprensa lida com a realidade social e suas complexidades.

\section{SOBRE A EMERGÊNCIA DO CRACK NO BRASIL}

O Brasil viveu distintos momentos e ciclos no que diz respeito à emergência das drogas no país e aos problemas advindos das toxicomanias. Entre as drogas ilícitas mais conhecidas e consumidas até hoje, a maconha teria sido a primeira trazida para o Brasil por escravos africanos. Outro ciclo considerado importante foi o uso de cocaína e heroína por integrantes da elite brasileira, no início do século XX (SAPORI e MEDEIROS, 2010, p. 95). Sem restrição legal, a cocaína era vendida livremente no Brasil, até sua proibição definitiva em 1938 (RESENDE, 2008).

Após a proibição da venda de algumas drogas (em outras configurações químico-farmacológicas, a cocaína era comprada sem restrições no país, no início do século, em farmácias e outros comércios), o Brasil - que adotou medidas de intolerância e combate à droga, como em muitos países, especialmente nos Estados Unidos - passou a coibir a venda e o uso de uma série de drogas, definidas a partir de então como entorpecentes.

No entanto, desde o início da década de 1990, o crack tornouse a maior novidade e a droga de maior impacto social no Brasil: seja pelos seus efeitos sobre os usuários, seja pelo fato - o que também foi considerado uma novidade - de se tratar de uma substância psicoativa relativamente barata e, por isso mesmo, de fácil acesso. Além disso, o uso do crack foi logo associado ao crescimento da criminalidade violenta e do número de homicídios.

Outro aspecto que diz respeito ao modo como se estabeleceu o comércio da droga é que o crack, segundo estudos mais recentes, é distribuído a partir de uma ampla rede de pequenos empreendedores. Desse modo, um funcionamento em redes - uma dinâmica de conexões entre seus componentes - faz emergir um padrão de organização. Nessas redes, pequenos empreendedores, gerentes e "soldados" atuam na venda e circulação da droga. Não sem motivos, a droga é associada à ampliação das situações de risco social e pessoal: aumento da violência e criminalidade, ao fortalecimento de grupos criminosos, ao crescimento do número de moradores de rua, à desagregação familiar, entre 
outros7.

Os relatos sobre o crack, presentes nos mais diversos campos e dispositivos sociais - da clínica aos aparatos policiais e da assistência social à mídia -, revelam, em geral, situações fortemente preocupantes de esgarçamento institucional, degradação de laços sociais e banalização da vida. Os envolvidos com o crack - usuários, geralmente também repassadores da droga - estão cotidianamente expostos a riscos das mais distintas naturezas: os próprios efeitos da droga em si; a violência inerente ao crime do tráfico; e, como acontece com muitos consumidores de crack, o de viverem expostos nas ruas. Depois de mais de duas décadas de distribuição e consumo no país, o crack é ainda objeto de mitos e desconhecimento sobre muitos dos aspectos relacionados à droga.

Lançado em 2012, o site do governo federal brasileiro Crack, é possível vencer8 destaca, em um de seus links, alguns mitos mais recorrentes. Entre eles, está o de que o crack gera dependência logo na primeira experiência de uso. Além deste, um mito sempre mencionado é o de que é consumido apenas pela população de baixa renda. Outro mito apontado em relação à droga é o de que o usuário torna-se uma pessoa violenta. O site, de responsabilidade do Ministério da Saúde, tenta desmontar alguns desses mitos, esclarecendo que a droga está presente em todas as classes sociais; que apesar de seu efeito intenso e bastante rápido, não há nenhuma prova de que o crack cria dependência com uma única experiência de uso e que, ao contrário do que muitas vezes as próprias autoridades policiais afirmam e a mídia divulga, a violência não é uma conduta padrão do usuário.

Estima-se que o crack tenha entrado em Belo Horizonte, vindo de São Paulo, na metade da década de 1990. Até então, conforme relatos registrados na pesquisa O desafio do crack (SAPORI e MEDEIROS, 2010), o tráfico de drogas distribuía na capital mineira basicamente maconha e cocaína, não havendo registro expressivo de distribuição de drogas pesadas como a heroína e o LSD.

Sapori e Medeiros (2010) apontam ainda que, nos primeiros anos da presença do tráfico do crack na capital mineira, não se verificou aumento do número de homicídios, mas que - e os próprios autores ressaltam que não se pode creditar tal ampliação exclusivamente ao crack - em menos de dez anos, depois do início da disseminação da droga na cidade, o número anual de homicídios em Belo Horizonte praticamente quadruplicou (SAPORI e MEDEIROS, 2010), passando de cerca de 300 homicídios, em 1996, para mais de 1200 em 2004. Os pesquisadores 
observam que, no que diz respeito aos impactos em termos da violência, pode-se falar em três fases da chegada e do estabelecimento da droga na cidade: um primeiro momento de chegada e evolução estável (1990 a 1996); um segundo momento de forte crescimento de mortes associadas ao crack, denominada de "deterioração gradativa" (1997 a 2004) e uma terceira, e vigendo atualmente, de "evolução negativa", que se inicia em 2005.

\section{IMPRENSA, O CRACK E IMAGINÁRIOS SOBRE A DROGA}

As pesquisas que têm buscado avançar na compreensão do fenômeno do surgimento e explosão do crack na sociedade brasileira chamam a atenção para o registro, inclusive na imprensa, de dados, informações e histórias não exatamente comprovadas sobre o crack, mas que acabam sendo cotidianamente afirmados e reafirmados pelos jornalistas e também de entrevistas com usuários e seus familiares, traficantes, e mesmo policiais e agentes de saúde pública que prestam atendimento aos viciados.

Entre algumas dessas crenças e imaginários, estão, por exemplo, relatos que dão conta de que "se queimar a pedra uma vez já está viciado", "o crack mata em poucos dias", "a pessoa que fuma crack tem vontade de matar" e "o usuário de crack é irrecuperável". São percepções que, em nosso trabalho de observação dos jornais, foram, em distintos momentos desta última década e meia, colhidas e que, em intensidade que não foi objetivo desta pesquisar apurar, parecem contribuir para a constituição de fortes imaginários a respeito da droga, seus usuários e os modos como os agentes de segurança e da saúde pública lidam com eles.

Neste trabalho, tomamos a noção de imaginário social formulada a partir de Castoriadis. Nessa perspectiva, o imaginário social passa a ser entendido como um conjunto de relações imagéticas que atuam como memória afetivo-social de uma cultura, um substrato ideológico mantido pela comunidade. Trata-se de uma produção coletiva, já que é o depositário da memória que a família e os grupos recolhem de seus contatos com o cotidiano.

\footnotetext{
Uma vez criadas, tanto as significações imaginárias sociais quanto as instituições se cristalizam ou se solidificam, e é isso que chamo de imaginário social instituído, o qual assegura a continuidade da sociedade, a reprodução e a repetição das mesmas formas que a partir daí regulam a vida dos homens e que permanecem o tempo necessário para que uma mudança histórica lenta ou uma nova criação maciça venha transformá-las ou substituí-las radicalmente por outras (CASTORIADIS, 2004, p. 130).
} 
Sapori e Medeiros (2010) alertam para o fato de que os meios de comunicação, muitas vezes, acabam por alimentar e ampliar alguns dos mitos e exageros, construídos no senso comum, nos últimos anos, sobre a venda e uso do crack. São comuns as manchetes de jornal que apresentam o crack como personagem dotado de vida própria, mobilidade e poder destruidor. Assim interpretado, o crack agiria sobre a pessoa e ela, tomada por uma capacidade mágica e satânica, atuaria sobre a sociedade de forma devastadora.

As imagens destacadas pelo Estado de Minas mostram os espaços urbanos denominados "cracolândias", nos quais um acumulado de indivíduos deambula com aspecto repugnante. São pessoas sujas, misturadas ao lixo. Simultaneamente, elaboram-se narrativas com apelo emocional, realçando figuras impressionantes, mães desesperadas, que relatam experiências individuais traumáticas, centradas em tragédias familiares e episódios violentos. Não que isso não encontre correspondência na vida social, mas, no entendimento de Sapori e Medeiros (2010), a intenção dessas notícias parece ser a de estabelecer e legitimar uma relação direta com a demonização da substância e localizar e culpabilizar o indivíduo, concentrando, assim, a atenção da sociedade nesse "problema social" e, ao mesmo tempo, desviando-a dos debates sobre a dimensão estrutural socioeconômica, política, jurídica, clínica e cultural nas quais o crack e outras drogas estão implicados (SAPORI e MEDEIROS, 2010.).

\subsection{O discurso jornalístico e suas idiossincrasias}

Os estudos acerca das narrativas do jornalismo têm, nas últimas décadas, avançado no sentido de não apenas questionar as efetivas possibilidades de objetividade no exercício jornalístico, mas de como as chamadas narrativas do real estão sujeitas a condicionamentos e tangenciamentos de diversas ordens, os quais são impostos pela natureza desse tipo de discurso, e de como elas circulam e reverberam na sociedade, com suas determinações de caráter cultural, ideológico, psicológico, ético, deontológico, entre outros.

A partir das relações acontecimento/versões/notícia/ repercussões, os estudos teóricos sobre o jornalismo têm buscado compreender, de modo mais enfático, os processos que fazem com que determinado acontecimento torne-se de interesse dos jornalistas e ao se elevar à condição de acontecimento midiático, seja inscrito no amplo, pouco profundo e nem sempre coerente leito da noticiabilidade. Isso pode até parecer reforçar a sensação de que notícia é tudo aquilo 
que os jornalistas acham que é notícia, mas bem se sabe que nos entrecruzamentos de linhas de força, de enunciação e mesmo de fuga do campo da produção e da veiculação da notícia (DELEUZE, 2005), essa eleição em termos do que será noticiado/ressaltado/rejeitado/esquecido tem circunstâncias, elementos actantes e determinações bem mais complexos.

Alsina (1989), Traquina (2004), Rodrigues (1993), Souza (2000) e Pena (2005), entre outros, oferecem sinalização comum acerca do acontecimento jornalístico: é tudo aquilo que irrompe da superfície lisa da realidade. Sua transformação em notícia - a construção, como destaca Alsina (1989), de um mundo possível - resulta de complexos processos de produção simbólica que se definem nas instáveis relações de poder/saber próprios da comunidade jornalística, mas que, ao mesmo tempo, impactam e se mostram como resultado dessas ambiguidades, contradições e conflitos. Como destaca Traquina (2004),

\begin{abstract}
O jornalismo é "estórias" acerca da vida, das estrelas, das tragédias e dos espetáculos dos congressos partidários. O reforço do polo econômico, as mudanças nas estruturas econômicas das empresas em grupos multimídia, a crescente competitividade, acentuaram a integração do campo jornalístico no campo mais vasto do campo mediático (sic). Na definição e construção das notícias, a importância do que é importante não pode ser apagada pelo imperativo do que é interessante. Os imperativos da concorrência e a luta pelo brilho profissional na procura de furos e "exclusivas" não podem fazer esquecer o direito à vida privada e o poder do jornalismo de denegrir o bom nome. (TRAQUINA, 2004, p. 208).
\end{abstract}

Rebelo (2000) aponta o que, na percepção dele, podem ser entendidos como mecanismos de autentificação na construção do texto jornalístico. Para o autor, i) a redundância, ii) a apresentação de histórias paralelas, iii) a delegação do saber e iv) o recuo temporal são recursos que proporcionam ao texto da notícia características e circunstâncias ainda mais fortes de verossimilhança.

Entre outros elementos, a análise de notas, notícias e reportagens veiculadas pelo jornal Estado de Minas sobre o crack no período de uma década e meia - desde a época de surgimento da droga na capital mineira, em 1996, até 2011 - confirmou a presença, de maneiras distintas, desses mecanismos apontados por José Rebelo (2000), e por meio deles para tentar perceber como, no estabelecimento do discurso jornalístico, a imprensa acaba por constituir e alimentar imaginários em relação ao crack ou concorre para uma simplificação que pode levar, muitas vezes, à opacização dos complexos aspectos envolvidos na questão.Sobre a redundância, Rebelo (2000) lembra-nos que título, lide, gravuras, legendas e textos reiteram insistentemente a repetição 
do sentido. "A redundância procura prender o leitor, convidando-o ao reencontro constante com aquilo que já conhece" (Rebelo, 2000, p. 110). É como se o leitor, na verdade, procurasse no jornal a confirmação dos elementos que já fazem parte de seu universo referencial - uma confirmação que, no entendimento de Rebelo - "é a chave da fidelização".

Já apresentar histórias paralelas produziria o efeito de caracterizar positiva ou negativamente um personagem ou um tema, por meio também da caracterização positiva ou negativa de personagens e enredos colaterais, com os quais a história central tem "evidentes nexos de causalidade" (REBELO, 2000, p. 110). Por sua vez, a delegação do saber pode ser percebida nos modos e formas de inscrição das vozes narrativas dentro do enunciado jornalístico. Como aponta Rebelo, quando o jornal dá a palavra a alguém, esse alguém ocupa lugar de destaque e em diálogo explícito com os direcionamentos da abordagem definidas pelo repórter. Segundo o autor, o leitor fica como que exteriorizado ao ato de comunicação, assistindo ao que acontece no palco.

Por fim, o recuo no tempo que, segundo Rebelo (2000), atualiza o passado, transportando virtualmente o leitor para o momento da ocorrência do acontecimento - e por que ocorrido seria, então, indesmentível. A operação narrativa seguinte, estabelecido esse nexo temporal, é fazer com que o leitor siga o caminho percorrido pelos próprios fatos no seu desenrolar.

\section{METODOLOGIA DE ABORDAGEM E ANÁLISE DO CORPUS DE PESQUISA}

Em sua íntegra, a pesquisa - da qual faz-se aqui relato conciso investigou a cobertura do crack pelo jornal Estado de Minas, alicerçando suas perspectivas teórico-conceituais a partir de distintos campos de conhecimento: por um lado, o da comunicação, enfatizando-se os estudos mais recentes sobre os processos de midiatização e os estudos teóricos do jornalismo, buscando entender como este engendra os discursos que distribui para a sociedade; por outro lado, o campo das ciências sociais, com destaque para os estudos e pesquisas de campo acerca do tráfico de drogas e a violência urbana associada a este.

Um dos desafios da pesquisa empírica no campo da comunicação social certamente está nos adequados seleção e dimensionamento do corpus ou corpora. Para esta pesquisa, procedemos a uma aproximação inicial de nosso objeto já com uma demarcação temporal definida, ou seja, quinze anos entre 1996 e 2011 , tomando como ponto zero de observação as primeiras notícias veiculadas pelo Estado de Minas sobre o crack até o ano de 2011 , haja vista que esta pesquisa teve início em 
2012, considerando prudente estabelecer como limite o ano completo de 2011 . Destaque-se que nosso ponto de interesse foram os textos noticiosos, focando a atenção na primeira página e no caderno Gerais do Estado de Minas, que reúne nas notícias de "cidade" e o noticiário policial. Portanto, não foram consideradas eventuais menções sobre o crack em editoriais ou outros cadernos/editorias do periódico.

Bardin (1988) e Barros e Targino (2000) (apud DUARTE; BARROS, 2005), assinalam que entre as principais regras para a constituição do corpus estão as seguintes: i) regra da exaustividade: todos os documentos relativos ao assunto pesquisado, no período escolhido, devem ser considerados, sem deixar de fora nenhum deles por qualquer razão (dificuldade de acesso, extravio, material desinteressante etc.) e ii) regra de representatividade, ou seja, as pesquisas sociais, de modo geral, abrangem um universo de elementos tão grande que se torna impossível considerá-los em sua totalidade, sendo necessário trabalhar com uma amostra.

A composição do corpus foi estruturada assim: em termos do formato, foram coletadas notas, notícias e reportagens que abordaram o crack, distinguindo-as quando a droga era percebida como sendo apresentada como citação, citação relevante ou assunto principal. Assim, para cada formato noticioso, tivemos, já na fase de coleta, a distinção do dado coletado em relação ao modo de presença do crack naquele item.

O pré-teste nos sinalizou que entre os anos de 1996 e 1999, as menções sobre o crack eram ainda em número bem reduzido, sendo que, em relação ao acervo disponível e disponibilizado pelo jornal para consulta, conseguimos acesso de modo integral, nesses quatro anos, apenas aos meses de fevereiro, junho e outubro. Tal circunstância nos pareceu um prejuízo para a observação, mas, pelo menos nos garantia uma estabilidade e coerência em termos de uma mínima regularidade.

Assim, para esta pesquisa, em função dessas circunstâncias e tendo em vista que nosso objetivo definia-se por amostra extensa - uma década e meia de cobertura jornalística - elegeu-se a regra da representatividade (tanto em função da opção de exclusivamente nos debruçarmos sobre os textos noticiosos e em função da impossibilidade de acesso a todas as edições do período 1996/99), definindo-se, portanto, uma amostragem cobrindo três meses de cada um dos anos entre 1996 e 1999 (Quadro I) e todos os meses dos anos de 2000 até 2011 (Quadro II), em atenção aos objetivos específicos propostos inicialmente, especialmente o de observar alterações nos modos de inscrição do crack na cobertura jornalística. 
Destaque-se que, ao todo, foram consultadas - de modo a serem computados todos os textos noticiosos em que houve a menção à palavra crack - 55 edições de jornais na primeira fase (1996 a 1999)9 e 807 edições na segunda fase da observação (2000 a 2011)10. Feitas as devidas seleção e categorização, obtivemos os resultados assinalados nos quadros 01 e 02 .

Os quadros permitem depreender informações relevantes a respeito da ampliação da presença da cobertura sobre o crack no Estado de Minas. Uma delas é a de que esse aumento coincide com o período em que a droga passa a ser associada mais fortemente à criminalidade e à violência, especialmente a ocorrência de homicídios. Como destacam Sapori e Medeiros (2010), os homicídios ligados diretamente ao crack - disputas, acertos de dívidas e enfrentamentos entre usuários/ fornecedores - tiveram curva ascendente a partir do ano de 1996, atingindo seu ápice em 2004.

Quando se analisa no jornal a alusão ao crack por modo de incidência, observa-se que nos dois períodos e nos três tipos de formato - notas, notícias e reportagens - a referência à droga como mera citação é uma constante. No caso das notas, a mera citação alcança entre os anos de 2000 e 2011 o total de 231 ocorrências. Já no caso das notícias, a mera citação está presente em 440 textos analisados e, no caso das reportagens, em 99 registros. Como citação relevante, no período de doze anos (2000 a 2011), o crack aparece em apenas quatro notas; já as notícias são 21 ; e nas reportagens, a citação relevante aparece em 35 textos. Como assunto principal, também considerado o período 20002011 , no que diz respeito às notas, o crack surge em quatro edições. Em termos de notícias, ele aparece em apenas dois textos e, no caso das reportagens, o crack foi assunto principal em 15 textos.

No que diz respeito aos formatos, destaque-se o grande número de notícias (463), quando comparado ao de notas (238) e reportagens (149). Nesse sentido, o registro acentuado de reportagens sobre o crack a partir do ano de 2009 sugere que a droga teve sua presença mais intensificada no jornal, acompanhando, certamente, a agudização dos processos de crescimento da venda da droga na capital mineira e o agendamento do tema pela sociedade como debate relevante. 

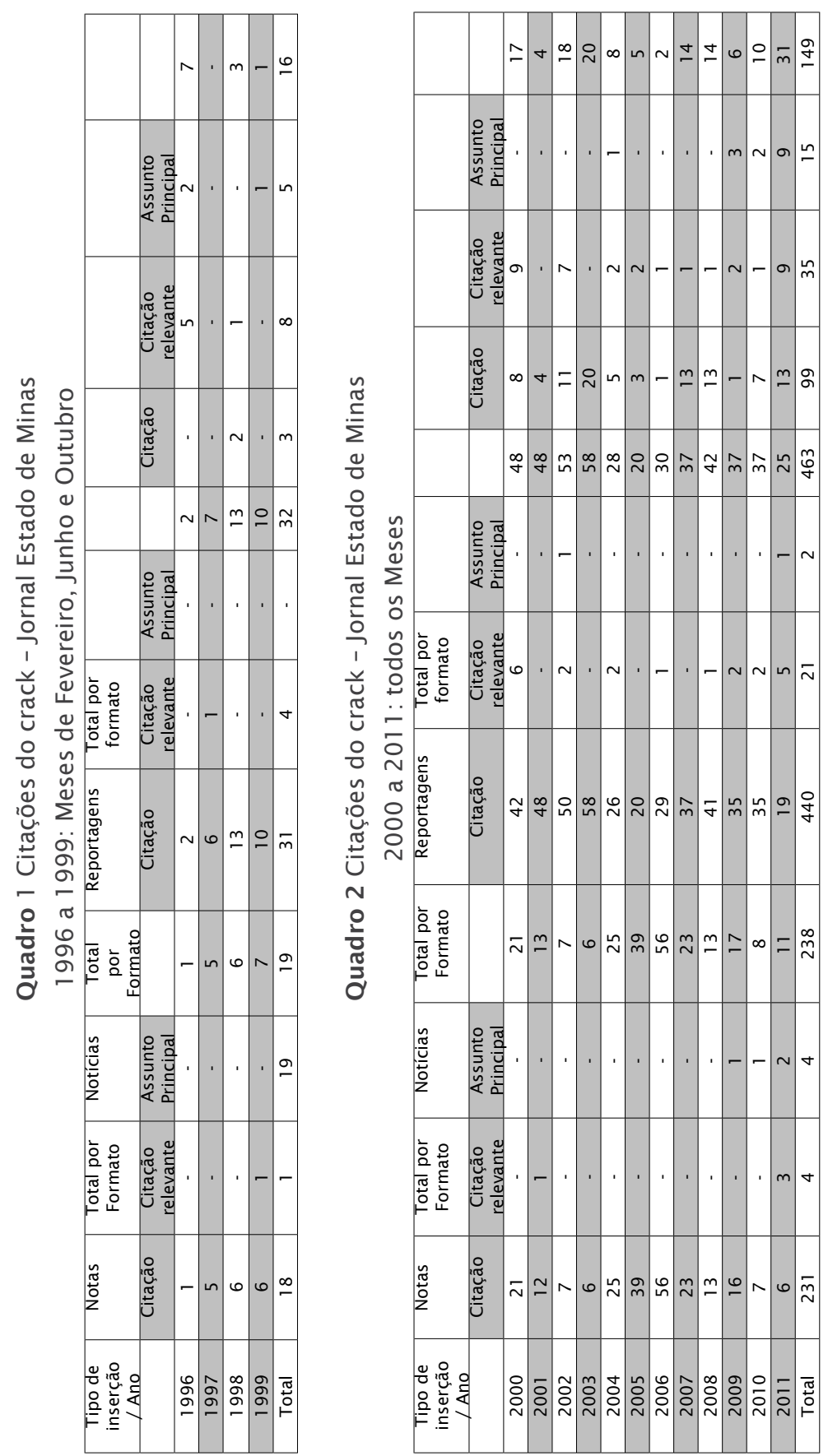


\subsection{Discussões acerca dos enquadramentos do crack e seus impactos na sociedade}

Entendendo que a observação quantitativa das menções ao crack no jornal Estado de Minas ofereceu importantes inferências no que diz respeito à hipótese deste estudo, ou seja, os modos de abordagem do crack pela imprensa, partimos então para outra etapa da investigação para tentar compreender mais claramente como se dá, por meio do jornalismo, os modos de construção das representações e imaginários sociais sobre o crack - desde o seu surgimento até a explosão da droga nos anos mais recentes. Nosso foco foi o de procurar entender, também, como o discurso jornalístico em relação à droga alterou-se nos últimos anos.

Um primeiro olhar sobre o objeto empírico sugeriu-nos que, no momento inicial da chegada da droga, prevaleceu, além da desinformação a respeito do crack uma tendência ao reforço, percebido nos conteúdos veiculados, de alguns mitos e imaginários existentes em relação ao crack, seus usuários e aspectos como sua distribuição, comercialização e efeitos farmacológicos. Posteriormente, os discursos emanados pelo Estado de Minas estabeleceram um movimento pendular que oscilou entre esta visão inicial e percepções e tentativas outras de compreender o fenômeno do crack na amplitude de sua complexidade em termos sociais, econômicos, de saúde e de segurança pública.

Nessa perspectiva qualitativa, foram adotados, assim, dois parâmetros de observação, iluminados e orientados pela analítica de conteúdo. Com essa metodologia, pretendeu-se atravessar o pouco transparente campo de produção dos sentidos do jornalismo para nele poder perceber como muitas das representações e imaginários acerca do crack foram sendo constituídos entre o surgimento da droga e os anos que se seguiram com sua rápida popularização, especialmente entre os integrantes de grupos de baixa renda e marginalizados.

Para a análise de conteúdo das mencionadas reportagens, além de observarmos os quatro pontos destacados por Rebelo (2000), denominados pelo autor de mecanismos de autentificação, optamos, ainda, por constituir categorias outras de observação, a saber: as qualificações associadas ao termo crack, como adjetivos e predicações; indícios de fetichização do crack, destacando aí situações em que à droga é relacionado um "poder" que vai além das consequências que objetivamente ela pode causar e, por fim, inferências possíveis em termos de imaginários a respeito da droga.

Em geral, as reportagens do Estado de Minas sobre o consumo 
e comércio do crack em Belo Horizonte tentaram apresentar ao leitor, por um lado, com dados bem objetivos, como o tráfico da droga se expandiu na capital mineira. Por outro lado, e ao mesmo tempo, os textos buscaram mostrar as graves consequências sociais e pessoais do consumo da droga: implosão das relações familiares, desemprego, miserabilização dos usuários, aumento da criminalidade e da violência e morte precoce. Importante destacar que em distintas edições, no período analisado, seja por impressões repassadas pelos próprios repórteres ou por entrevistados, alguns dos mitos e imaginários mencionados neste artigo foram reforçados.

Esta pesquisa não suspeita, a priori, que a imprensa comete sistematicamente exageros em suas notícias e reportagens a respeito do crack. É de domínio público, certamente, como a proliferação da droga no Brasil - alguns autores já falam em universalização, o que daria a ela uma circunstância epidêmica - já apresenta consequências seriíssimas. $\mathrm{O}$ que moveu o trabalho foi o pressuposto de que as narrativas que substanciam a cobertura jornalística, muitas vezes, menos esclarecem e, por vezes, em tom emocional/alarmista, acabam por reforçar mitos e incompreensões a respeito desse grave problema social.

No trabalho analítico, buscamos observar, em todos os textos noticiosos, os aspectos mencionados acima. Do conjunto analisado, consideramos as menções a seguir como as que merecem destaque e em que ao crack são associadas as seguintes qualificações e predicações que foram ao encontro das questões que este artigo apontou como hipótese:

\section{Adjetivos 1 1:}

pedra maldita; pedra da morte;

alucinador; ameaça do momento;

prima pobre da droga do

brilho; primo pobre do pó branco; pedra do cemitério; droga da violência; droga assassina; vilão da epidemia.

\section{Predicativos 12:}

(os excertos apresentados a seguir foram extraídos das reportagens analisadas e consideradas de maior relevância)

i. "Crack invade salas de aula em BH" (ESTADO DE MINAS, 25/08/1996).

ii. "[...] o crack já invadiu as favelas e centros urbanos e seus consumidores não conseguem largar o vício, mesmo sabendo dos males provocados pela droga" (ESTADO DE MINAS, 19/05/1996). 
iii. "Droga forma exército de traficantes e aumenta índices de criminalidade" (ESTADO DE MINAS, 23/10/1996).

iv. "Subproduto da cocaína, é geralmente fumado em cachimbo caseiro. O efeito da pedra chega rápido ao cérebro. A droga super excita (sic) os impulsos nervosos e dá ao viciado uma sensação de euforia. Em pouco tempo a pessoa pode ser levada à morte por hemorragia cerebral, convulsão e infarto do miocárdio" (ESTADO DE MINAS 23/10/1996).

v. "Crack cria 'super-homens'”. (ESTADO DE MINAS, 27/10/1996).

vi. "Nessa guerrilha urbana, a batalha pode ser pela posse de poucas pedras de crack. Aliás, a droga é apontada como principal responsável pelos assassinatos, pois seu comércio é desorganizado, e os jovens surgem como soldados despreparados" (Estado de Minas, 12/03/2000).

vii. "Por outro lado, a polícia parece impotente diante da avalanche do crack, a moeda mais forte do mundo do crime e que patrocina a maioria das tragédias que atingiram muitas famílias na Capital neste semestre (ESTADO DE MINAS, 11/06/2001).

viii. "Crack municia atiradores" (ESTADO DE MINAS, 25/09/2005).

ix. A droga que descobriu o Brasil. Antes restrito aos grandes centros urbanos, o crack chega às pequenas cidades (ESTADO DE MINAS, 25/11/2009).

x. Em menos de 20 anos, a droga invadiu o país, sem distinção de classe social, geográfica ou etária (Estado de Minas, 25/11/2009). xi. Crack invade o interior (Estado de Minas, 25/11/2009).

xii. Um terço dos homicídios em Belo Horizonte ocorreu por causa do tráfico de drogas. E o vilão da epidemia tem nome: crack (Estado de Minas, 27/08/2010).

xiii. Tudo por causa do crack (Estado de Minas, 15/12/2011.)

xiv. Sob domínio do crack (Estado de Minas 08/11/2011).

xv. Antes limitada à área central, população de rua se multiplica por toda a capital, transformando-se em desafio inflacionado pelo crack. Apesar da percepção de que o fenômeno está se agravando, BH não dispõe de dados oficiais atualizados (ESTADO DE MINAS, 05/10/2011).

xvi. As pedras são a ameaça do momento (ESTADO DE MINAS, 05/10/2011).

Observe-se que, em relação a excertos como os de $\mathrm{n}^{\circ} \mathrm{i}$, ii, iii, ix, $x, x i, x i i, x v$ e xvi, mesmo que se possa entender que a construção 
enunciativa estrutura-se como um "modo de dizer" figurativo, não se pode desconsiderar que a droga, mesmo com seus conhecidos nexos de causalidade e graves efeitos, ganha, por meio da narrativa, um status de ator social, em um processo também de fetichização, em que passa-se a ideia de que o crack - a pedra - por si só, tem a força de provocar efeitos sociais terríveis. Além disso, a droga é associada ao trágico e ao mal, no sentido de possuir poderes "diabólicos"- oferecendo ao leitor uma imagem satanizada da droga. Ou seja, o crack, em termos da construção narrativa, ganha tratamento de um ator social - um "personagem" do jornalismo - deixando de ser tratado como - o que seria mais correto um elemento integrante de uma cadeia complexa de nexos causais e de uma rede de acontecimentos e circunstâncias.

Chamou também a atenção o fato de as reportagens utilizaremse fortemente dos mecanismos de autentificação, a partir de Rebelo (2000), como já mencionado neste artigo. No caso dos eventos narrativos em que se observa a redundância, as reportagens valem-se de um curioso artifício de reafirmação, a todo momento, da ideia principal que abordam. Recuperando aqui o que afirmou Rebelo (2000), o leitor é convidado ao constante reencontro com aquilo que já sabe. Para tanto, podem ser tomados como exemplos os excertos de $\mathrm{n}^{\circ} \mathrm{i}$, ii, vii, xi, xiii e xiv, onde os enunciados trazem uma abordagem não apenas redundante em relação às informações tratadas, mas também com claro teor generalizante, sendo que para a comprovação de tais argumentos, o texto se vale, inclusive, de relatos de entrevistados e suas respectivas histórias.

Sobre esse aspecto, uma reflexão que se mostra muito relevante, mas que a extensão deste artigo não permite desenvolver, diz respeito a um tipo de ocorrência narrativa que não é tão incomum nos textos jornalísticos - sejam eles impressos ou eletrônicos: uma certa tendência, por assim dizer, à generalização, que no transcurso da notícia/ reportagem será sustentada por exemplos/depoimentos descritos pelo repórter. Como exemplo, podem-se citar, em relação às reportagens analisadas, afirmações como: "Droga forma exército de traficantes e aumenta índices de criminalidade" (ESTADO DE MINAS, 23/10/1996)"; "Tudo por causa do crack" (ESTADO DE MINAS, 15/12/2011); ou "Crack invade salas de aula em BH" (ESTADO DE MINAS, 25/08/1996).

Além disso, a delegação de saber é um recurso recorrente nas reportagens analisadas. As fontes/entrevistados relatam suas experiências como usuários ou na condição de familiares de viciados. Um processo que, obviamente, segue as estruturas narrativas próprias 
e comuns às textualidades jornalísticas, ou seja, relatos geralmente em terceira pessoa com a convocação de testemunhos, cujos discursos são apropriados e articulados ao discurso do repórter, resultando daí um novo discurso, o jornalístico, que se materializa por meio de formatos específicos, entre eles, os analisados neste estudo: a nota, a notícia e a reportagem. A reportagem "A vida não vale nada no mundo da droga", veiculada no dia 02 de abril de 2000, é um bom exemplo desse mecanismo ao apresentar o depoimento da mãe de um traficante encarcerado. Identificada como "Maria", a mãe expõe ao jornal o seu drama:

\begin{abstract}
"Eu não desprezo meu filho por nada deste mundo", desabafa a mãe de um traficante preso que, por causa do medo que sente, pede para ocultar ambos os nomes e a região onde moram. "Maria" segue a linha dura entre as mães do tráfico. Sabia do negócio em que o filho estava metido, chamava a sua atenção, impedia que entrassem drogas na sua casa e nunca usufruiu do dinheiro do tráfico, apesar de ser doente e viver da pensão do ex-marido (ESTADO DE MINAS, 02/04/2000).
\end{abstract}

Na reportagem "Crack: a droga da violência", veiculada em 30 de maio de 2004, um usuário, identificado como PAT, de 29 anos, reforça a ideia de que basta usar o crack por uma vez para se tornar um dependente da droga e também uma certa percepção de um poder que a droga possuiria:

\footnotetext{
Fui preso no meio das Lojas Americanas tentando pegar um CD, troquei tiros com a polícia e até pulei da passarela da rodoviária. Eu sempre fui ligeiro e isso garantia meu vício. Mas antes de virar um trombadinha mendigo, eu trafiquei para sustentar a fissura que começou desde a primeira vez que coloquei o cachimbo na boca (ESTADO DE MINAS, 30/05/2004).
}

Por fim, o recuo no tempo que, segundo Rebelo (2000), atualiza o passado, transportando virtualmente o leitor para o momento da ocorrência do acontecimento - e por que "ocorrido, indesmentível". É como que levar o leitor ao momento zero - instante que separa o passado do futuro, o que, para Rebelo, importa numa "mutação qualitativa que a narrativa não contempla" (REBELO, 2000, p. 111), e, por isso mesmo, "o leitor mergulha, na verdade, em um mundo já não do realizado, mas do realizável que a narrativa antecipou". Um exemplo é a entrevista concedida ao jornal pelo juiz da Infância e da Juventude de Belo Horizonte, Geraldo Claret. Na reportagem "Jurados de morte", publicada na edição do dia 13 de outubro de 2001, o juiz aborda em entrevista como os jovens acabam sendo cooptados pelo tráfico: 
Durante o dia, eles são deixados à sua própria sorte nos bairros de periferia, nos morros, sem encaminhamento para escola de qualidade, trabalhos profissionalizantes ou esporte. A hora em que falta o gás dentro de casa ou que o menino quer comprar um tênis novo, o traficante se apresenta para emprestar o dinheiro. A partir do momento em que o adolescente faz o primeiro serviço para o traficante, está selada uma sociedade mortal. (ESTADO DE MINAS, Estado de Minas13/10/2001).

\section{CONSIDERAÇÕES FINAIS}

As observações relativas a uma década e meia (1996-2011) das inscrições sobre o crack no jornal Estado de Minas, da capital mineira, confirmaram a hipótese inicial da pesquisa "Representações do crack na imprensa mineira: imaginários do jornalismo sobre a droga, os traficantes, usuários, policiais e agentes de saúde pública": a cobertura sobre o fenômeno do crack acaba por reforçar, de modo enviesado, em função de características e peculiaridades próprias do fazer jornalístico e das narrativas produzidas por este campo e pelo modo como as mídias se fazem presentes na sociedade, aspectos mais agudizados da questão e, em determinados momentos e circunstâncias, mais opacizando do que contribuindo para uma melhor compreensão e debate sobre a droga.

É importante considerar, no entanto, e assim se deu ao longo de toda a pesquisa, que as perspectivas mencionadas sobre o submundo do crack devem sempre, por correção e cuidado, ser relativizadas no sentido de entender que, a despeito da discursividade da imprensa que, muitas vezes, embrenha-se por operações que mais relevam o mítico, o sensacional e o espetáculo em detrimento da informação esclarecedora - não se pode perder de vista que a droga produz efeitos gravemente danosos aos seus usuários e propicia também, de modo efetivo, circunstâncias e permanentes riscos de esgarçamento das relações familiares e do tecido social como um todo.

Como se deve destacar também que se, por um lado, e também paradoxalmente, essa mesma cobertura do crack apresenta, em determinados momentos, discussões e debates que efetivamente contribuem para iluminar o tema, por outro lado, a droga recebe alusões que remetem a uma fetichização e a um tratamento que se afasta dos processos e ocorrências em si. O crack é valorizado, como se disse, como um ator social dotado de superpoderes devastadores. Uma cobertura que faz com que as visões oferecidas pelo jornal esbocem-se, muitas vezes, em edições subsequentes, em uma sucessão pendular entre o sensacional e mítico e a descrição objetiva e mesmo reflexiva. 


\section{NOTAS}

1. A pesquisa "Representações do crack na imprensa mineira: imaginários do jornalismo sobre a droga e agentes envolvidos" tem o apoio da Fapemig (Fundação de Amparo à Pesquisa do Estado de Minas Gerais) e foi realizada de março/2012 a março/2013.

2. Entende-se aqui jornal de referência como os periódicos da imprensa escrita que se estabeleceram tradicionalmente na imprensa brasileira, possuindo, além de efetiva abrangência em termos de circulação, inegável poder de influência junto à opinião pública, sendo, por esses aspectos, dentre outros veículos, tomados como referência pela sociedade.

3. Segundo pesquisa da Confederação Nacional dos Municípios (CNM), o crack já está presente em $98 \%$ das cidades brasileiras.

4. O trabalho de levantamento e tabulação das matérias e reportagens contou com a colaboração da bolsista e graduada em Jornalismo da PUC Minas, Jeane Caroline de Oliveira Moreira.

5. Ver quadros p. 10 e 11.

6. O jornal Estado de Minas foi fundado em 7 de março de 1928 em Belo Horizonte. O diário, conhecido como o grande jornal dos mineiros, tem o formato standard e também está disponível, para assinantes, na versão digital. Atualmente possui circulação de aproximadamente 112 mil exemplares aos domingos (Fonte: IVC).

7. No final de 2010 , uma pesquisa da Confederação Nacional de Municípios (CNM) sobre a situação do crack nos municípios brasileiros revelou que 98\% das cidades pesquisadas enfrentavam problemas com a presença do crack e outras drogas. Um estudo do Instituto Nacional de Pesquisa de Políticas Públicas do Álcool e Outras Drogas (Inpad), da Universidade Federal de São Paulo (Unifesp), divulgado em setembro de 2012, mostrou que a cocaína fumada (crack e oxi) já foi usada pelo menos uma vez por 2,6 milhões de brasileiros, representando 1,4\% dos adultos. Os adolescentes que já experimentaram esse tipo da droga foram 150 mil, o equivalente a 1\% deste grupo. O Brasil responderia, segundo o Inpad, por cerca de $20 \%$ do consumo mundial de cocaína e crack.

8. Fonte: http://www.brasil.gov.br/crackepossivelvencer/home

9. Por ano, o quantitativo de textos analisados é o seguinte: 1996 (9); 1997 (10); 1998 (18) e 1999 (18). 
10. Por ano, o quantitativo de textos analisados é o seguinte: 2000 (79); 2001 (68); 2002 (75); 2003 (77); 2004 (60); 2005 (59); 2006 (78); 2007 (69); 2008 (71); 2009 (58); 2010 (52) e 2011 (61).

11. As inscrições adjetivantes que apresentavam efeitos semânticos idênticos ou muito similares foram desconsideradas.

12. Idem para as predicações

\section{REFERÊNCIAS}

ALSINA. Miquel Rodrigo. A construção da notícia. Petrópolis: Vozes, 1989.

BARDIN, Laurence. Análise de conteúdo. Lisboa: Edições 70, 1988.

BIRD, S. Elizabeth e DARDENNE, Robert W. Mito, registro e estórias: explorando as qualidades narrativas das notícias. In TRAQUIINA, Nelson (Org.). Jornalismo: questões, teorias e estórias. Lisboa, Vega, 1993 (p.263).

CASTORIADIS. Cornelius. As encruzilhadas do labirinto: os domínios do homem. v.6. Rio de Janeiro: Civilização Brasileira, 2004.

DELEUZE, Gilles. O mistério de Ariana. Lisboa: Vega, 2005.

DUARTE, Jorge; BARROS, Antonio. (Orgs.). Métodos e técnicas de pesquisa em comunicação. São Paulo, Atlas, 2005.

PENA, Felipe. Teoria do Jornalismo. São Paulo: Contexto, 2005.

REBELO, José. O discurso do jornal: o como e o porquê. Lisboa: Editorial Notícias, 2000.

RESENDE, Beatriz. Cocaína. Rio de Janeiro: Casa da Palavra, 2008.

RODRIGUES, Adriano. O acontecimento. In: TRAQUIINA, Nelson (Org.). Jornalismo: questões, teorias e estórias. Lisboa: Vega,1993.

SAPORI, Luiz Flávio; MEDEIROS, Regina. Crack: um desafio social. Belo Horizonte: Editora PUC Minas, 2010.

SOUSA, Jorge Pedro. As notícias e seus efeitos. Coimbra: Minerva, 2000.

TRAQUINA, Nelson. O estudo do jornalismo no século XX. São Leopoldo: Editora Unisinos, 2001.

\section{Edições do Jornal:}

ESTADO DE MINAS. Belo Horizonte: Associados.

25/08/1996; 19/05/1996; 23/10/1996; 27/10/1996; 12/3/2000;

$11 / 06 / 2001 ; \quad 13 / 10 / 2001 ; \quad 30 / 05 / 2004 ; \quad 26 / 09 / 2005 ; \quad 25 / 09 / 2009$;

27/08/2010; 05/10/2011;08/11/2011;15/12/2011. 
Mozahir Salomão Bruck é jornalista e pesquisador do Programa de Pós-graduação em Comunicação Social da PUC Minas. Doutor em Literaturas de Língua Portuguesa pela PUC Minas e mestre em Comunicação e Cultura pela UFRJ.

E-mail:mozahir@uol.com.br 